\title{
Iranian Feminist Activists and Critical Media Literacy
}

\section{Kobra Mohammadpour Kachalmi}

\author{
Corresponding Author, \\ Ph.D candidate in the Department of \\ Civilization and Government Studies, \\ Faculty of Human Ecology at Universiti Putra Malaysia
}

Lee Yok Fee

Associate Professor, Department of

Civilization and Government Studies,

Faculty of Human Ecology at Universiti Putra Malaysia

Doi: $10.2478 / \mathrm{mjss}-2018-0160$

\begin{abstract}
Considering the exponential growth of technology and media in Iranian society as well as the significant role of media culture in reproducing, reinforcing, and legitimizing dominant ideologies such as sexism, the central question posed by this paper is how Iranian feminist activists critically analyze media messages. Further, this paper explores the extent to which this analysis fits the critical media literacy framework. Using a critical media literacy framework underpinned by feminist standpoint theory, this paper presents results from qualitative interviews with 15 Iranian feminist activists. We find that Iranian feminist activists focus more on politics of representation and critique of gender ideology in the critical analysis of media products. Thus, critical analysis of media by Iranian feminist activists better fits the definition of critical media literacy than its core concepts. The findings also demonstrate that a transformative dimension of critical media literacy is ignored by the feminist activists despite using media in the struggle against dominant gender ideology.
\end{abstract}

Keywords: Critical media literacy, Ideology critique, Iranian feminist activists, Sexism, Politics of representation

\section{Introduction}

As in other parts of the world, the exponential growth of technology, as well as various media, are rapidly changing Iran's society and making Iranians more media-focused and networked. The head of Iran's Information Technology and Digital Media Division of Ministry of Culture reports that Iranians spend an average of 5 to 9 hours a day in the digital world (Jozi, 2016). In 2017, around 56 million Iranians used the Internet and about 17 million used Facebook ("Internet usage," 2018). According to Secretary of the Supreme Council of Cyberspace, Iranians were prominent users of social media in 2016, including 24 million Telegram users, 12-14 million Instagram users, and 14 million WhatsApp users ("Number of Telegram, Instagram," 2016). In addition to digital media, Iranians also have access to various national and satellite TV channels, spending around 4 hours per day watching TV (Dabirimehr, 2016).

Within this context, media plays a prominent role in shaping Iranian identities. As Kellner (2011) points out, the media provide models of what it means to be male or female, successful or unsuccessful, powerful or powerless. Media culture also provides the materials out of which many people construct their sense of class, ethnicity, race, and gender. 
In this regard, Iranian women are imbued with sexist ideology through various media outlets. As an example, Iran's national TV, which is controlled by the dominant political system, indoctrinates Iranian women into the patriarchy via the oppressive representation of gender through TV series and commercials. Studies of Iran's national TV series and commercials revealed how TV reproduces gender divisions of labor, in which women are shown to operate in private spheres while men are deemed proper for public existence (Ahmadi , Agili , \& Mehdizadeh, 2015; Azin \& Tabrizi, 2015).

Additionally, despite the banning of satellite by Iran's hardliners, women are indoctrinated into sexism through satellite TV programs. Analyzing Turkish satellite TV series that are popular in Iran demonstrates that women are represented as dependent, nosy, blabbering, dumb, jealous, passive, easily obtained, sexual objects, devoted mothers, and good wives. Gender division of labor and patriarchal family systems that limit the power to make decisions to males are reinforced in most series (Orta, 2013; Rahmani, 2016; Sari, 2016).

Because problematic and negative representations of women have harmful consequences in reinforcing social and gender inequalities, it is imperative for Iranian women - an oppressed group and the consumers of various media - to become fully aware and conscious of what they are being shown through various media outlets. It is also important for Iranian women to understand to what extent and for what purpose the information affects women's thought processes, attitudes and behaviors (Sharda, 2014). They must understand how the media reinforce and perpetuate sexism through biased representations of women. In addition to critically understanding media, Iranian women must also be empowered to use media for advancing ideals of gender equality when doing so attacks or weakens sexism by representing gender more positively.

Despite the importance of critical media literacy for empowering Iranians, particularly female Iranians, it has not found a place in either formal or informal education in Iran. There has also been a lack of research on critical media literacy among Iranian women. The current study first examines how Iranian feminist activists critically analyze media and to what extent their analyses fit our current understanding of critical media literacy. In the second section, we examine the literature concerning media literacy among Iranian women. In the third section, we discuss the theoretical framework of critical media literacy and feminist standpoint theory. Data collection methods are described in the fourth section. In the fifth and sixth sections we present and discuss findings regarding the critical analysis of media by Iranian feminist activists. In the final section, our conclusions are presented.

\section{Literature Review on the Studies on Media Literacy in Iran}

Despite the ubiquity of media in contemporary Iranian society, and its prominent role in socializing and educating Iranian women, media education has not yet been developed or considered either in schools or outside the classroom. There is also a paucity of studies on media literacy in Iran, particularly among Iranian women. As such, this section examines the few existing studies conducted on media literacy among Iranian women.

Zendehboodi and Zendehboodi (2011) examined the relationship between media literacy and the impact of commercials on female students in Allame Tabatabaei University. This study investigated the extent to which media literacy influences students' purchasing behavior and their subsequent assessments of the trustworthiness of brands. Using questionnaires, the authors show that students with more media literacy are less influenced by commercials.

By studying the behavior of 410 women in Shiraz city, Bahmani and Bostani (2015) replicate the positive effect of media literacy by demonstrating that consumerism decreases with increasing media literacy.

Fazelian Dehkordi and Mohammadi (2017) examined the relationship between media literacy and consumption of cultural products such as books, newspapers, journals, music, TV, and the Internet among women in Kurd City. Using the same questionnaire technique, the study showed that women's consumption of cultural products increases with increasing media literacy. Additionally, the consumption of cultural products is higher among women who know the owner of the media. 
Similarly, Solhi, Jormand, and Gohari (2016) studied the effect of media literacy on students' attitudes toward self-medication with slimming supplements in female dormitories at the University of Medical Sciences in Iran. The authors presented 98 females with a media literacy questionnaire. They showed that mean scores for attitudes about body image, self-esteem, and dimensions of media literacy in both a test and a control group were moderate, with no significant differences between groups prior to a quasi-experimental media literacy education intervention. One and three months after the intervention, however, mean scores for attitudes about body image, self-esteem, and dimensions of media literacy were significantly enhanced in the control groups. These results demonstrate that media literacy education can be effective in improving attitudes about slimming supplements.

Using the same method, Khazir, Dehdari, Majdabad, and Tehrani (2016) also found positive effects of media education on cosmetic enhancement in females. These authors examined the role of media literacy education on female students' attitudes about cosmetic surgery from two women's dormitories at Tehran University of Medical Sciences. This study provides evidence that media literacy education can significantly impact female students' opinions on elective cosmetic surgery, as well as increase self-esteem and decrease body dissatisfaction.

Acknowledging the high rates of Internet consumption by Iranian women, Montazerghaeim and Sahabn Kasegar (2015) investigated how the virtual activities of Iranian women are affected by their critical media literacy. They investigated this link using a questionnaire presented to 429 Iranian women who were identified to be active in cyberspace. They found that women with higher critical media literacy used the Internet more for motivating others, influencing people's thoughts, sharing knowledge and skills, and expressing themselves creatively.

The literature review on media literacy among Iranian women demonstrates an apparent lack of studies about media literacy despite important role of media in shaping identities. All quantitative research conducted to date indicates that media education can reduce the risks of media usage, such as consumerism. As observed, most studies have used a protectionist approach to media literacy by considering how media literacy may reduce the negative effects of media consumption. Because the study of critical media literacy among Iranian women remains relatively unexplored, the current study aims to explore critical media literacy among Iranian feminist activists.

\section{Theoretical Framework}

In order to generate questions, develop data collection and analysis methods, and select informants for the present study, we used critical media literacy and feminist standpoint theories.

\subsection{Feminist Standpoint Theory}

Standpoint theory describes a way to empower oppressed groups such women by valuing their experiences (Harding, 2004). According to the theory, women "need to understand the conceptual practices of power through which their oppression was designed, continued and made to seem natural and desirable to everyone" (Harding, 2004, p. 7). In order to gain power and fight gender discrimination, women need to understand how gender oppression works in different ways, and how the subordination is made not only to seem natural but indeed desirable. As Masterman (2003) states, pervasive ideas such as dominant gender ideology are not just imposed, but often appear to be acceptable, and even to speak to the interests of subjugated groups such as women. To stand against oppression, women need to be empowered. Moreover, women must to be taught that gender marginalization is not a natural genetic byproduct it is not in their best interests, and it does not generate happiness, as they are often indoctrinated to think.

According to feminist standpoint theory, a critical understanding and recognition of oppressive situations is easier and more achievable for subjugated groups such as women than for groups who do not directly experience oppressive structures themselves. This is the case because subjugated groups have directly experienced problems and issues which are produced by oppressive structures (Narayan, 2004). While experiencing oppression may facilitate critical thinking about oppression, understanding oppressive structures is not an automatic result of being in a 
subordinate situation.

Feminist standpoint theory represents more than just the views and experiences of oppressed women. "The moment of critical insight is one that comes only through political struggle for it is blocked and its understandings obscured by dominant, hegemonic ideologies and the practices that they make appear normal or even natural" (Harding, 2004, p. 9). In fact, developing critical insight requires collective, intellectual and political struggle to uncover the structures of oppression (Share, 2009).

As the media play a prominent role in perpetuating gender oppression, making it seem natural and desirable to women, women must gain knowledge to understand the oppressive structures that normalize sexism and empower themselves to fight against gender oppression, both collectively and individually. Women need to perceive how gender discrimination and the subordination of women are designed, perpetuated, and normalized through their representation in media. Therefore, feminist standpoint theory proposes to first reveal hegemony and domination in media representations (Share, 2009). Perceiving and understanding oppressive gender representation is a starting point because doing so will help those involved to comprehend the complex power relationships of oppressive structures and the normalization of gender oppression through media representations.

In following feminist standpoint theory, the present study selected Iranian feminist activists for interviews. Because they are members of the oppressed group, they can more easily discern oppressive structures of gender in media representations. As the theory notes, a critical understanding of oppressive structures does not occur automatically because one is a woman. In fact, developing critical insight requires collective, intellectual, and political struggle (Share 2009). Hence, Iranian feminist activists who have experienced political struggle against gender oppression were selected for the study, in order to explore their critical insights on media.

\subsection{Critical Media Literacy}

Given the power of media culture in shaping gender identity and perpetuating dominant oppressive gender ideologies, it is increasingly vital to critically understand media. In this regard, gaining critical media literacy is important for everyone, particularly for women as an oppressed group, in order to identify the oppressive gender representations in media that indoctrinate women into a sexist ideology and normalize gender discrimination.

Given a number of different perspectives, there is currently no consensus among scholars regarding media literacy. Kellner and Share (2005) classified the different perspectives into four categories. Based on their classification, the first perspective in media education is called the protections approach, which is underpinned by a fear of media and has an anti-media bias. The second approach is called media art education, which only considers the production of art and media without a critical approach. This helps to reinforce hegemonic representations and dominant ideologies. The third approach is the media literacy movement which downplays ideological critique (Livingstone, 2013). The cultivation of a critical consciousness and civic participation do not play a role in this approach (Thevenin, 2012).

The fourth approach identified by Kellner and Share (2007), is critical media literacy. This approach originates from the idea that an active media audience can resist media hegemony. Moreover, they can use media for their emancipation. Active audiences need to be able to read media messages critically and recognize dominant ideologies and values encoded in media. The recognition of hegemonic values and ideologies is important because these are often invisible in media messages and products.

Critical media literacy includes aspects of the three previous models with a focus on the critical dimension, which explores and criticizes the structure of oppression and domination in media messages. For Kellner and Share (2007):

Critical media literacy focuses on ideology critique and analyzing the politics of representation of crucial dimensions of gender, race, class, and sexuality; incorporating alternative media production; and expanding textual analysis to include issues of social context, control, and pleasure. (p. 8) 
Therefore, the proposed critical analysis approach incorporates both criticism of ideologies embedded in media and an analysis of the representation of gender, race, and ethnicity in media messages (Kellner \& Share, 2009). Studying ideology encourages "readers to perceive that all cultural products have distinct biases, interests, and embedded values, reproducing the point of view of their producers and often the values of the dominant social groups" (Durham \& Kellner, 2009 , p. xiv). This approach to the study of media is designed to help people become more sensitive to the ways in which the media reflect, reinforce, and shape ideological systems (Silverblatt, Ferry, \& Finan, 2015)

Thus, in engaging a critical analysis of media, "notions of ideology and hegemony, as well as the 'politics of representation' in media (which includes dimensions of sexism, racism, classism and homophobia, to name a few) are central concerns" (Hammer, 2009, p. 184). This is a crucial step in critically analyzing media; without this step, oppressive representations perpetuate discrimination and injustice.

Since critical media literacy is a transformative pedagogy which works towards democracy and justice, it empowers people to engage in counter-hegemonic representation. A non-critical analysis of media content does not allow an audience to take action against hegemony and oppression. As critical media literacy includes political acts and is connected with democracy and social justice, it requires leaners and citizens to question media and create alternative representations that challenge media underrepresentation and misrepresentations (Funk, Kellner, \& Share, 2016).

In the case of gender, critical media literacy focuses on gender representations and sexist ideologies. In doing so, it generates critical questions which cast doubt on specific portrayals of gender (lyer \& Luke, 2011). Discerning gender ideology involves analyzing gender stereotypes and roles. The audience must engage in analyzing codes and signals that re-frame the stereotypes. Thus, critical media literacy helps people question the social construction of gender and sexism and refute the popular link of gender with biology and genetics (Funk et al., 2016).

As previously discussed, Iranian women are indoctrinated into sexist ideology through various national and international media sources. Hence, they need to be empowered to perceive the ways in which media transmits sexist ideologies - ideologies which could influence their thoughts, behaviors, and acceptance of an oppressive gender ideology. Drawing on Kellner (2003), this kind of critical inquiry of media representation would liberate Iranian women to think outside of oppressive ideologies and seek new political and social alternatives. It can bring them together participating in political movements fighting for social transformation. Without critical media literacy, gender-based oppression is harder to question; women will be less likely to challenge existing gender-based subordination systems.

A critical media literacy framework guides the current research. This theory is appropriate for application in Iranian society because Iranians are imbued with dominant system gender ideologies through state broadcasting as well as more general sexist ideologies through international satellite TV channels. Here, we explore the ways in which Iranian feminist activists analyze media critically, and the extent to which their analyses adhere to a critical media literacy framework. Towards this aim, this study employs core concepts of critical media literacy for analyzing data. Drawing on Funk et al. (2016), as well as Kellner and Share (2007), critical media literacy has six core concepts which guide data analysis:

Social Constructivism: All information is co-constructed by individuals and/or groups of people who make choices within social contexts. This involves understanding that media products are not neutral and transparent but are instead socially created and shaped. Thus, they represent reality by offering a biased selection of a socially created reality.

Languages / Semiotics: Each medium has its own language with specific terminology and semantics. All media products have their own analyzing languages, genres, codes, and conventions.

Audience: Individuals and groups understand media messages similarly or differently depending on multiple contextual factors. This concept involves exploring the active role of audiences in negotiating meanings in the meaning-making process.

Politics of Representation: An examination of the process of representation in media reveals issues of bias, point of view, ideology, omission, aesthetics, power, privilege, and pleasure within 
the products' content and the influence of the medium.

Production / Institutions: All media products have a purpose (often commercial or political) that is shaped by the creators and/or systems within which they operate. A critical analysis of the institutions of production helps to identify goals and aims (e.g. profit or power) of media products.

Social Justice: Media message are not produced in vacuum; they impact and influence people within societies. Questioning racism, classism, and sexism in media helps to identify how some people and groups benefit more than others from media messages, as well as how some groups are further marginalized.

\section{Method}

The aim of this research is to explore how Iranian feminist activists critically analyze media messages and how much of their analyses adhere to a critical media literacy framework. Because of the paucity of research on critical analysis of media in Iran, we have used a qualitative approach to examine this topic. We have followed a semi-structured interview method to explore people's knowledge, views, understandings, interpretations, experiences, and interactions, all meaningful properties of social reality (Mason, 2002).

Study informants were selected via a method of purposeful sampling. "Purposeful sampling researchers intentionally select individuals and sites to learn or understand the central phenomenon" (Creswell, 2012, p. 206). Based on feminist standpoint theory, Iranian feminist activists were selected as informants with at least three years experiences in struggling against gender discrimination in Iran's society. Since they are actively involved in political struggles against gender oppression and inequality in Iran. Because of their involvement, they have critical insights about female subordination and marginalization. Since most Iranian feminist groups are placed and active in Tehran, then feminist activists in Tehran were selected for the interview in 2016. Fifteen Iranian feminist activists were interviewed through a snowball sampling method in which key informants were asked to propose other suitable informants for the study (Creswell, 2012).

Thus, semi-structured interviews were carried out with the feminist activists to explore their analysis of media productions. Examples of some media products, such as TV series, were provided to informants. Following the examples, informants were asked how they would critically analyze certain media products. Subsequent data analysis and discussion followed a critical media literacy framework, with an emphasis on certain core concepts. It should also be mentioned that all names are pseudonymous.

\section{Findings}

Fifteen Iranian feminist activists were interviewed on how they critically analyze media products, such as TV. Data analysis was guided by the core concepts of critical media literacy. The current research reveals that the politics of representation and the aim of media messages are the most important concepts in critical analysis of media message by the Iranian feminist activists.

\subsection{Politics of Representation}

The politics of representation was the most important concept for the Iranian feminist activists. This concept involves "examining the processes of representation, to uncover and engage issues of bias, point of view, ideology, omission, aesthesis, power, privilege, and pleasure in the content of the text" (Share, Funk, \& Kellner, 2016, p. 1). Iranian feminist activists focused on gender representation politics by analyzing sexist ideologies. They criticized gender roles, stereotypes, male domination, and misrepresentation of women in media messages, particularly in TV series and advertisements. For example, Diana, a 38-year-old woman, stated that gender roles are the most important thing for her own critical analysis of media content:

The first thing that I notice [in criticizing media messages] is gender roles. If the role is traditional, the man works outside, and the woman stays at home. If she washes dishes, the man watches TV. 
In analyzing media messages for gender roles, Diana considered whether portrayed gender roles are traditional and whether the division of labor is based on gender. Specifically, she noted whether women who are portrayed in media stay at home to do chores while men go outside the home, with little to no housework responsibilities. In this way, she identified dominant sexist ideologies in which women are confined to the domestic sphere.

In addition to criticizing gender-based division of labor within family settings, Diana also critiqued power relations in her critical reading of media:

Next, I see how a woman in the family [in a TV series] has the power to choose...how a woman participates in making decisions ...how much men force [women to do something] ... . In my view critical analysis means criticizing power relations.

Diana focused on hierarchical power relations in family structures and the extent to which women have power to make decisions, select things they want, and the inverse, how much power men have to compel women.

Aysan, a 39-year-old activist, analyzed women's status in the family and society as well as gender stereotypes portrayed in media such as movies:

[I notice] how it [i.e. a movie] defines women's status... what certain aesthetic stereotypes are portrayed [by the actress]. For example, how those [stereotypes] link to current stereotypes... how it represents a woman's status in the family, society, and her workplace.

This informant noted women's status in society while criticizing media messages, particularly in movies and TV dramas. She was concerned about how women's positions in the family and in workplace settings are portrayed in media. She also focused on beauty stereotypes, which link actresses to current societal stereotypes.

Likewise, Melina, a 44-year-old woman, pointed to gender stereotypes and roles used in media content, with a focus on misogynist terminology:

[I notice] whether they promote gender stereotypes. If they reproduce gender stereotypes that promote traditional roles of women and emphasize that women should stay at home... Misogynistic gender stereotypes which are represented in media are important and considered by us [feminist activists] and whether they [the media] use some words which are misogynist.

Six other Iranian feminist activists, Anahita, Parnian, Mana, Arina, Kiana, and Tarrannom also identified gender stereotypes and roles, power relations between women and men, patriarchal ideals, and the social status of women when they analyzed media products of Iran's national TV programs.

In addition to noticing sexism in media messages, two of the feminist activists, Shafigeh and Anahita, examined ethnic ideologies in their critical reading of media messages. Shafigeh, a 32year-old woman, said:

One [thing I notice] is sexism and another thing is how they show equality among people...for example, equality between an Afghani and Iranian.

She noticed equality among people in media messages, along with identifying sexism. As an example, she identified a lack of equality between two national identities, Iranian and Afghani, particularly for Afghanis who have immigrated to Iran. Thus, one of the feminist activists in our sample of informants added ethnocentrism to her analysis of the politics of representation in Iranian media.

Similarly, Armita, a 30-year-old activist, believed that understanding sexism is not enough. Her critical analysis of media was based on intersectionalism:

For me, because I am a feminist, [the first thing I analyze in media] is gender, but I am an intersectional feminist. Ethnicism makes me angry as much as sexism does. Classism makes me angry as much as sexism does. The combination of ethnic, class and gender discrimination is important to me. 
As a feminist activist, the first thing to take note of is how gender is represented in media. Armita, however, came from an intersectionalist perspective; along with sexism, she criticizes classism and ethnicism.

Analyzing media content also requires questioning omissions in media representation (Kellner \& Share, 2007). Some of the feminist activists paid attention to omissions when analyzing media materials critically. Specifically, they considered omissions of different groups, counter-hegemonic representations, and censorship. Melina, a 44-year-old woman, said:

Another thing I consider [in critical analysis] is that different voices cannot be heard in the [Iranian] state media. This is national TV, but there are no different voices ...only one group has a voice in the media.

Along with analyzing gender stereotypes, Melina also observed whether or not different voices belonging to different groups are heard in the media. She believed that Iran's national TV should belong to all Iranian citizens and, as such, it should represent different groups existing in Iran. In reality, however, only one group has a voice and other groups are omitted from the dialogue. In addition, she identified censorship in media, particularly from Iran's national TV:

The most important thing in our media is censorship, which leads you to be not informed about many things...this also includes women's issues. Women's issues are not just gender stereotypes or sexism... Some things happen about women, there are some damages, these have never been portrayed in media.

Media censorship, such as is perpetrated by Iran's national TV programming, removes any information which is not deemed publicly appropriate, particularly when it relates to oppressed groups such as women. Melina asserted that women's issues extend beyond sexism and the representation of gender stereotypes. Many other issues relating to women are censored from TV programming which have never been shown. In contrast to Melina's view, the wider censorship of women's issues can also be considered a form of sexism, because women's issues are generally omitted from media representation.

Similarly, Tarannom, a 34-year-old activist, explained how the media only represent a limiting, dominant view of women:

There are different characters [except dominant represented gender stereotypes] for women, they react differently about their issues and this is omitted in the media [Iran's national TV].

As Tarannom explained, there are individual differences among women in Iran. Women have different characters and think differently about various issues. Iran's national TV, however, represents only one kind of woman. It only portrays women who behave according to the gender ideologies of the dominant political system; all others are omitted.

Together, the findings demonstrate that the most important issue for Iranian feminist activists is the politics of representation. As they are feminist activists who struggle against gender discrimination, they focused on how gender ideology and sexism are represented in media. The Iranian feminist activists identified how media products such as TV series and advertisements reinforce gender-based oppression by representing gender stereotypes, gender-based division of labor, and biased status and power relationships between women and men. Ethnicism and classism were identified in media messages by some of the feminist activists as well.

Omission of variation and perspectives in media is another issue which some of the feminist activists pointed out in their analyses. Omission occurs predominantly by the dismissal of media representations for different groups, for counter hegemonic representations of women, and through the censorship of current events in society, particularly when topics relate to groups of oppressed and marginalized people, such as women.

Considering these findings, it should be noted that Iranian feminist activists focused on reading dominant ideologies - particularly sexism - in media materials. In so doing, they targeted a central component of Kellner and Share (2007) definition of critical media literacy: ideology critique. 
They recognized sexist ideologies and values, which are often invisible in media products. They discerned how media portrays gender roles, stereotypes and male domination in the family and in society more widely. In identifying these biases, Iranian feminist activists explored how sexism and patriarchal ideologies are transmitted.

\subsection{Aim of Media Messages}

In addition to the politics of representation, some of the Iranian feminist activists perceived the aims of messages in their critical reading of media products. Five activists, Parnian, Mitra, Ava, Hora, and Anahita paid attention to the goals and aims media products convey. To illustrate this concept, Parnian, a 28-year-old woman, explained:

For example, I see many [of Iran's national] TV programs suddenly start to represent and talk about issues such as polygamy. All [of the national] TV channels show series about it. I understand this should not have happened by accident. Probably there is an agenda behind this... and this shows there is a system behind this and this is the dominant system because media [like Iran's national TV] is not independent."

Parnian discussed the fact that media, particularly Iranian national TV, is not independent. As such, understanding the aims of media messages should be considered in any critical reading. This is what Parnian identified when she used the example of polygamy being shown on all of Iran's national TV channels; this could not be mere coincidence. Because Iran's national TV is politically controlled, depicting polygamy is a goal-directed pattern that the system pursues for its own political gains.

Ava, a 33-year-old woman, also noticed the aims behind media messages:

For example, Kimia, a TV series, showed an educated woman who left her job to take care of her child... This [representation] means why the woman should study? It also means that the woman is taking [the] place of a man in university... The aim and function of this representation is to perpetuate the subordination of women. And media is used for this aim on purpose.

Ava presented an example of a famous series, which was being broadcast on Iran's national TV at the time of interview. She explained how representing women as housewives and caregivers has broader aims than simply representing gender stereotypes and roles. As she discussed, when Kimia, represents an educated woman who leaves her job in order to take care of her children and housework, this portrayal is intentional. It aims to show that if women study at university they take the place of men, a detrimental move for society. University is commonly seen as a place for men, not women. The main aim of the representation is legitimatizing and perpetuating the subordination of women by domesticating them, urging them to stay at home even when they are qualified with a university degree. Indeed, the aim of the TV series is to perpetuate the sexist ideologies of the political system.

Mitra, a 38-year-old woman, asserted:

The things the [media] messages tell should be doubted...and that whose interests it [i.e. the media] defends. Because in my view, media is not neutral... National media [in Iran] basically supports the powerful who have access to more resources and can exploit or subordinate others. That is why in my view, critical analysis is to suspect those who are defended and whose power is legitimized by the messages.

Understanding the goals behind media messages could also be accomplished by recognizing the power and interests of specific groups that are represented in media products. For a critical analysis of media content, one should consider which group's power and interests are represented. For example, Iran's national TV supports the interests of the powerful: those who have more resources and can exploit and marginalize others. Thus, a critical analysis must consider whose power is legitimized in media messages. This helps to identify the aims of the media, which is often to maintain the status quo and protect the interests of those who have power. 
Hora, a 32-year-old activist, explained how by identifying the director of the media message, the aim of media products can be better discerned:

The first thing is good faith and that we should see the behind of those events. Sometimes you can see a man beats his wife [i.e. in a movie]. Someone maybe believes it promotes violence...but when I analyze I will say that it wants people to think about that (i.e. violence). When it represents a woman to have been beaten, it does not mean that [beating one's wife] is right and good... It maybe represents social issues and problems.... For understanding good faith, we should see the director's resume... when I watched the movie, Two Women, by director Tahmineh Milani, I know that she is a feminist activist... [then,] if in the movie the man beats his wife it does not mean this is right, but this shows lack of law [i.e. of domestic violence] to audiences.

According to Hora, when you know the director of a movie, you will understand the aim of the messages portrayed in the movie. For example, if one knows that a director has a feminist perspective, even though she represents violence against women, she does not mean to oppress women and signal approval of violence. Instead, the director's intention is likely to criticize violence against women and the lack of legal action against it. In this way, the aims of media messages can be understood by knowing who creates the messages, and the particular ideology adhered to by the creators.

As it mentioned earlier, all media products have a purpose (often commercial or political) that is shaped by the creators or system within which they operate (Funk et al., 2016). In this regard, critical media literacy encourages citizens to question why the messages have been sent and where they come from (Kellner \& Share, 2007). The findings presented here also indicate that some of the feminist activists believe that media has specific aims and that understanding these aims is integral for their critical analysis of media.

\subsection{Alternative Representation}

Only one of the feminist activists indicated the importance of alternative representations. Mahnoosh stated that alternative representations should also be taken into account for a critical analysis of the dominant representation of women in media:

In my view, an alternative should be given [in critical analysis]. When a woman who has children gets divorced or her husband is died, [representing that she] gets remarried and experiences love again is an alternative... Or a woman who is patient while she is beaten, humiliated and [still she] remains in that life, the alternative is representing a strong woman who gets divorced and can stand the difficulties of divorce.

In Mahnoosh's view, critical analyses of media messages should also provide an alternative and counter hegemonic representation. When the media outlet, such as Iran' national TV, subordinates women by only representing the dominant view of gender, in which women receive violence, devote themselves to their children, and do not attend to their own needs, a critical analysis should offer an alternative portrayal of women. She explains that when Iran's national TV portrays a divorced woman who spends the rest of her life alone, a critical analysis should consider an alternative in which, for example, a divorced woman or widow remarries and experiences love again. Likewise, when TV programs portray women who are patient in the face of violence, a critical analysis should provide an alternative in which the violated women are strong, take action against violence, and seek divorce.

Since critical media literacy is transformative (Funk et al., 2016), it should be involved in empowering women to question gender representations in media. Further, critical media literacy should create alternative representations that challenge oppressive misrepresentations of women. Mahnoosh considered the transformative role, which involves criticizing negative representations of women while forming alternatives. Indeed, by examining patriarchal relations in media that produce anti-hegemonic gender representations, women can become empowered agents to foster gender equality. 


\section{Discussion}

Drawing on core concepts of critical media literacy, the findings of this study demonstrate that the politics of representation are the most prominent concepts considered by Iranian feminist activists in their critical analysis of media messages. As they are themselves feminists, they focused on gender representation politics and they perceived gender roles, stereotypes, and hierarchal gender relations in media products. Iranian feminist activists identified dominant gender ideologies such as sexism in their critical reading of media. Dominant sexist ideologies are conveyed by the regular portrayal of women in domestic spheres and by the representation that this domain is appropriate to a woman's nature. Criticizing male-dominated hierarchies in which women have lower status, less power in the family, and are dominated by men are other aspects of sexism, which Iranian feminist activists took notice of in media products. In a few cases, they also took notice of ethnicism and classism. Additionally, with regards to the politics of representation, informants observed the omission of different groups from representation. This omission of counter-hegemonic representations fails to portray women as acting differently from the dominant gender ideology. The omission also includes omitting issues and problems relating to subordinated groups such as women.

Another concept that some of the Iranian feminist activists considered in their critical analyses was related to the institutions of production. They pointed out that because media in Iran are controlled by the dominant political system, they have intentional aims of reproducing dominant ideologies about gender. Media such as Iran's national TV tries to reinforce sexist ideologies held by the dominant group with sexist representations that legitimize the status of those who are in power.

As the findings indicate, Iranian feminist activists focused on only two of the six core concepts of critical media literacy. They highlighted the politics of representation and the aims of media messages. The remaining four core concepts did not play a role in their critical readings of media products. The activists did not analyze media languages in their critique of media products. All technical and creative aspects of media production, including the choice of camera angles, color schemes, and the visual and audio techniques used were left out of their critical readings. This is noteworthy because the use of camera angles can make products appear larger or women appear smaller and more diminutive (Luke, 2003). A high camera angle, for example, looking down on actors, could make a woman appear less powerful and less significant or even submissive, while a low camera angle causes them to appear more powerful or dominant. Further, in their critical reading of media products, Iranian feminist activist did not perceive how media languages and techniques play a role in the subordination of women and the reproduction of dominant ideologies.

Differentiation in audiences' understanding and interpretation of media products was also absent in the observed critical analyses. Grasping this notion develops a "pluralistic democracy which depends on perceiving multiple perspectives as a natural consequence of varying experiences, histories, and cultures constructed within structures of dominance and subordination" (Kellner \& Share, 2007, p. 14). Not one of the informants mentioned how individuals and groups understand media messages similarly and/or differently depending on multiple contextual factors such gender, ethnicity, class, or experience. The activists did not pay attention to the active role of audiences in negotiating meanings in the media meaning-making process.

Another core concept that was ignored by the Iranian feminist activists is social constructivism, which highlights the fact that all media messages are constructed. This concept shows that media messages are not neutral or transparent, nor do they present objective reality, but a selection of reality. Often, they actively construct reality. Although one of the feminist activists mentioned that knowing the identity and perspectives of directors when analyzing media messages is important, it was only for discerning the aim of media messages, not in the context of considering the non-transparency of media messages themselves.

Although most Iranian feminist activists focused on ideology critique, particularly sexism, only two of them, took note of how oppressive representations of gender and marginalized groups could cause the further subordination of Iranian women and legitimize current power structures. This demonstrates that the concept of social justice was perhaps not prioritized in their critical readings 
of media. The concept of social justice helps to highlight the negative impacts of oppressive portrayals of gender on gender equality and, moreover, how the dominant group (i.e. males) benefits from the oppressive representations.

One important observation in the findings is that all the feminist activists, with the exception of only one, failed to consider the transformative dimensions of critical media literacy in their critical analyses of media. As discussed, critical media literacy is a transformative pedagogy and, as such, it should be involved in understanding oppression and acting against it. If utilized, it could empower the public - particularly women - to question gender representations in media. Additionally, it could create alternative representations to challenge the oppression and misrepresentation of women. In the present study, only one of the feminist activists mentioned creating alternative, anti-hegemonic representations when reading media products critically. The findings of this study demonstrate that, while the Iranian feminist movement regularly employs media, especially social media, in the fight against gender inequality and female subordination (Lerner, 2010; Michaelsen, 2011; Shojaee, 2016; Zangeneh, 2015), the feminist activists as a part of the movement did not embrace using the media in their critical analysis of media messages.

Taken together, this research reveals that critical analysis of media among Iranian feminist activist adheres largely to Kellner and Share's (2007) definition of critical media literacy, but not strictly to its core concepts. Iranian feminist activists did adhere to the notion of ideology and politics of representation which are central and emphasized in Kellner and Share's (2007) definition. In other words, Iranian feminist activists focused more on ideological critique and the politics of representation on gender than on the other core concepts of critical media literacy when they critically analyze media productions.

\section{Conclusion}

Given the important role of media in constructing Iranian feminine identity and reinforcing sexism (e.g. through national and satellite TV channels), and the fact that there is currently little research available investigating the critical analysis of media in Iran, particularly among Iranian women, this study seeks to expand the literature by investigating how Iranian feminist activists critically analyze media messages.

Using a qualitative approach with semi-structured interviews conducted with fifteen Iranian feminist activists, we have shown that the politics of representation are the most important concept of critical media literacy for the Iranian feminist activists' critical reading of media products. While Iranian feminist activists focus on gender representation politics and sexist ideologies in reading media critically, they do not frequently recognize other oppressive ideologies. Only a few of the Iranian feminist activists paid attention to racism and classism to the same extent that they focused on sexism when they criticized media content. The next core concept of critical media literacy that the Iranian feminist activists focused on in their critical analyses was the purpose of media products.

While the findings indicate that Iranian feminist activists failed to incorporate some concepts of critical media literacy in their critical analyses of media messages, we cannot conclude that these activists are not familiar with these concepts. These concepts are potentially not considered when they analyze media products critically, either because they do not think of them as relevant for a critical analysis of media. As the study demonstrates, only one of the fifteen Iranian feminist activists mentioned an alternative representation in her critical reading of media. Media, and particularly the Internet, play a significant role in the Iranian feminist movement; Iranian feminist activists have made extensive use of the Internet for their fight against the dominant sexist ideology and subordination of women (Lerner, 2010; Michaelsen, 2011; Shojaee, 2016; Zangeneh, 2015). Despite the prolific use of media by Iranian feminist activists for transforming and rendering sexism and gender oppression less effective, the activists do not yet utilize the transformative dimension of critical media literacy in their critical analysis of media representations. 


\section{References}

Ahmadi , S., Agili , S. V., \& Mehdizadeh, S. M. (2015). Semiotic analysis of gender identity in TV. Women in Culture and Art, 7(1), 1-16.

Azin, N., \& Tabrizi, H. H. (2015). Analysis of women's image in Iranian TV commercials based on Barthes visual semiotic. Mediterranean Journal of Social Sciences, 6(6 ), 415-422.

Bahmani , L., \& Bostani, D. (2015). Media literacy and consumerism (among women in Shiraz) Social Depelopment, 10(1), 187-212.

Creswell, J. W. (2012). Educational Research: Planning, Conducting, and Evaluating Quantitative and Qualitative Research. Boston: Pearson.

Dabirimehr, A. (2016). Four hours watching TV and six hours using mobile. Retrieved from https://www.isna.ir/ ( January 7,2017$)$

Durham, M. G., \& Kellner, D. M. (2009). Media and cultural studies: Keyworks. Malden: Blackwell.

Fazelian Dehkordi, M., \& Mohammadi, A. (2017). The effect of media literacy on consumption of cultural products focused on processing and analyzing of media messages. Quarterly Journal of Sicentific Research of Women and Society, 7(28), 51-90.

Funk, S., Kellner, D., \& Share, J. (2016). Critical media literacy as transformative pedagogy. In M. Yildiz \& J. Keengwe (Eds.), Handbook of Research on Media Literacy in the Digital Age (pp. 1-30). Hershey PA: IGI Global.

Hammer, R. (2009). This won't be on the final: Reflections on teaching critical media literacy. In R. Hammer \& D. Kellner (Eds.), Media/cultural studies: Critical approaches (pp. 164-193). New York: Peter Lang Publishing.

Harding, S. G. (2004). The Feminist Standpoint Theory Reader: Intellectual and Political Controversies. London: Routledge.

Internet usage, broadband and telecommunications reports. (2018). Retrieved from https://www.internetworldstats.com/me/ir.htm (April 25, 2018)

Iyer, R., \& Luke, C. (2011). Gender representations in the media and the importance of critical media literacy. In T. Steven, G. Bernardo P, H. Annette, B. G. Mary, \& P. Price (Eds.), Handbook of Research in the Social Foundations of Education (pp. 434-449). New York: Taylor and Francis.

Jozi, A. (2016). $60 \%$ of Iranians use Telegram as an entertainment source. Retrieved from http://techrasa.com (July 27, 2016)

Kellner, D. (2003). Media Culture: Cultural Studies, Identity and Politics Between The Modern and The PostModern. New York: Routledge.

Kellner, D. (2011). Cultural studies, multiculturalism, and media culture. In G. Dines \& J. M. Humez (Eds.), Gender, Race, and Class in Media: A Critical Reader (pp. 7-18). London: Sage.

Kellner, D., \& Share, J. (2005). Toward critical media literacy: Core concepts, debates, organizations, and policy. Discourse: Studies in the cultural politics of education, 26(3), 369-386.

Kellner, D., \& Share, J. (2007). Critical media literacy, democracy, and the reconstruction of education. In D. P. Macedo \& S. R. Steinberg (Eds.), Media literacy: A reader (pp. 3-23). New York: Peter Lang

Kellner, D., \& Share, J. (2009). Critical media education and radical democracy. In M. W. Apple, W. Au, \& L. Armando Gandin (Eds.), The Routledge international handbook of critical education (pp. 281-295). New York: Routledge.

Khazir, Z., Dehdari, T., Majdabad, M. M., \& Tehrani, S. P. (2016). Psychological aspects of cosmetic surgery among females: A media literacy training intervention. Global journal of health science, 8(2), 35.

Lerner, M. Y. (2010). Connecting the actual with the virtual: The Internet and social movement theory in the Muslim world-The cases of Iran and Egypt. Journal of Muslim Minority Affairs, 30(4), 555-574.

Livingstone, S. (2013). Children and the Internet. Cambridge: Polity.

Luke, C. (2003). Reading gender and culture in media discourses and texts. In G. Bull \& M. Anstey (Eds.), The literacy lexicon (pp. 196-208). Sydney: Prentice-Hall.

Mason, J. (2002). Qualitative Researching. London: Sage.

Masterman, L. (2003). Teaching the Media. New York: Routledge.

Michaelsen, M. (2011). Linking up for change: The Internet and social movements in Iran. In N.-C. Schneider \& B. Graf (Eds.), Social Dynamics 2.0: Researching Change in Times of Media Convergence (pp. 105-125). Berlin: Frank\&Timme.

Montazerghaeim, M., \& Sahabn Kasegar, M. (2015). Critical media literacy and cyber activity of women in Iran. Jounal Cultural Studies and Communication, 11(40), 186-230.

Narayan, U. (2004). The project of feminist epistemology: Perspectives from a nonwestern feminist. In S. G. Harding (Ed.), The feminist standpoint theory reader: Intellectual and political controversies (pp. 213-224). Routledge: London. 
Number of Telegram, Instagram and WhatsApp's user in Iran. (2016). Retrieved from http://www.asriran.com/fa/news ( December 7, 2016)

Orta, N. (2013). Women representations in television narrative in the context of popular culture and Turkey. Academic Journal of Interdisciplinary Studies, 2(8), 564.

Rahmani, M. (2016). Women Status in Turkish Series. Retrieved from [Online] Available: https://bidarzani.com ( February 1, 2016)

Sari, G. (2016). The Representation of masculinity in Turkish television series: "Eskiya Dunyaya Hukumdar Olmaz". International Journal of Advanced Research and Review, 1(10), 52-55.

Sharda, A. (2014). Media and gender stereotyping: The need for media literacy. International Research Journal of Social Sciences, 3(8), 43-49.

Share, J. (2009). Media Literacy Is Elementary: Teaching Youth to Critically Read and Create Media. New York: Peter Lang.

Share, J., Funk, S., \& Kellner, D. (2016). Critical Media Literacy framework. Retrieved from https://www.researchgate.net ( November 5, 2016 )

Shojaee, M. (2016). Women's voices: The journey towards cyberfeminism in Iran. ISS Working Paper Series/General Series, (621), 1-29. Retrieved from hdl.handle.net (October 18, 2016)

Silverblatt, A., Ferry, J., \& Finan, B. (2015). Approaches to media literacy: A handbook. London: Routledge.

Solhi, M., Jormand, H., \& Gohari, M. (2016). The impact of media literacy intervention on the female students' attitudes about self-medication of slimming supplements. Journal of Health Literacy, 1(1), 13-24.

Thevenin, B. J. (2012). Critical Media Literacy in Action: Uniting Theory, Practice And Politics in Media Education. (Unpublished doctoral dissertation), University of Colorado Boulder, Colorado.

Zangeneh, N. (2015). Bidarzani collective. Journal of Middle East Women's Studies, 11(3), 362. doi:https://doi.org/10.1215/15525864-3142570

Zendehboodi, k., \& Zendehboodi, F. (2011). The role of students' media literacy in impact of commecials on them Media Studies, 8(20), 169-180. 